\title{
Petición de perdón: ¿Reconocimiento de las víctimas?
}

El 16 de enero, como cada año, se conmemoró la firma de los Acuerdos de Paz realizados hace dieciocho años en el Castillo de Chapultepec, México. El presidente de la República, Mauricio Funes, en su calidad de máxima autoridad del Estado, y en nombre del mismo, pidió perdón por los crímenes cometidos en el pasado por los entonces cuerpos de seguridad y la Fuerza Armada, crímenes que se constituyeron como graves violaciones a los derechos humanos -persecuciones, abusos sexuales, desapariciones forzadas, torturas, asesinatos, masacres-, vejámenes cometidos contra amplios grupos sociales, en su mayoría civiles indefensos. Sin lugar a duda, se trató de un paso importante en el tránsito de la reconciliación salvadoreña, es decir, un primer paso en asumir las recomendaciones emanadas por la Comisión de La Verdad en su informe "De la Locura a la Esperanza"; entre las que se encuentran la reparación material y moral de las víctimas del conflicto. 
Si bien es cierto, tras los avances de los Acuerdos de Chapultepec, esto es, creación de la Procuraduría para la Defensa de los Derechos Humanos, Policía Nacional Civil, ratificación de tratados de Derechos Humanos, entre otros; poca o nula importancia dieron los anteriores gobiernos a las recomendaciones antes citadas. Ciertamente, de las instituciones creadas hay mucho por discutir, la fragilidad en la que se encuentra el Estado salvadoreño en su conjunto y la situación económica y social por la que atraviesa el país, representan una verdadera amenaza para la democracia que se está labrando desde el 16 de enero de 1992. Ahora bien, respecto a las recomendaciones ningún gobierno de la postguerra las acató, en su afán de intentar dejar atrás los años oscuros de la historia reciente salvadoreña, la derecha bajo el manto de un "perdón y olvido" conveniente a su bando, impuso sobre la sociedad su visión respecto a las víctimas. Y es que para los anteriores gobiernos el Estado no debía pedir perdón pues esto llevaría -necesariamente- a otro conflicto y destruiría la reconciliación y el anhelo de los salvadoreños: la superación del pasado doloroso, que a juicio de la derecha ya se ha logrado. De ahi entonces la importancia de la petición del presidente Funes, la paz se reafirma con el reconocimiento de esos graves errores, no podrá haber redención mientras existan víctimas marginadas, personas concretas sin ningún tipo de reparación y personas e instituciones concretas que cometieron los crímenes y que ahora representan la mejor cara de la impunidad. En definitiva, no habrá paz sin reconciliación y ésta se logra con la búsqueda de la verdad y la justicia.

Es evidente, que la importancia de la petición del Presidente Funes, como se mencionó arriba, radica en el avance hacía una verdadera dignificación de las víctimas. Asimismo, su discurso nos lleva al debate sobre las víctimas, y en concreto, sobre el protagonismo de éstas en todo el proceso; también nos sugiere el debate sobre un tema espinoso o sensible para la actual administración y, por supuesto, para las mismas víctimas, se trata de la ley de Amnistía. En su pretensión el ejecutivo no puede obviar dicho tema para alcanzar su propósito; en ese sentido, el presidente no puede asumir que las víctimas han concedido su perdón, pues muchas de ellas exigen justicia y ésta pasa por el señalamiento de los culpables de todos los vejámenes. En otros términos, la ley de Amnistía representa un verdadero reto tanto para el Ejecutivo como para los partidos políticos y por supuesto para la sociedad. Ciertamente, es competencia del órgano legislativo la derogación de la ley de Amnistía, sin embargo, el presidente Funes no puede separarse de esa discusión, pues hacerlo desdice la voluntad y el cambio que pregonó en su discur- 
so, y, a la vez, su petición correría el riesgo de quedarse en el tintero y convertirse en otro manto protector de la impunidad.

Por otra parte, el anuncio de la creación de una Comisión de reparación moral, simbólica y material y la Comisión de búsqueda de niñas y niños víctimas de desaparición forzada despierta expectativas y algunas dudas. Expectativas de grandes resultados en distintos sectores, principalmente en las víctimas y las organizaciones que las apoyan o acompañan, pues ambas comisiones, en efecto, son muestras o expresión de lograr una justicia restaurativa, la búsqueda de las personas desaparecidas es un esfuerzo legítimo y necesario para llegar a la verdad, por ello su labor deberá estar al alcance de toda la población, esto a través de informes u otros medios de reparación simbólica.

Ahora bien, las dudas surgen en buena medida por los integrantes que conformaran la primera Comisión, por los recursos con los que cuenta el Estado, específicamente para la reparación material, y por la verdadera voluntad de encarar esa deuda con la sociedad. Respecto a los integrantes de la Comisión de reparación, en primer lugar es cuestionable la falta de representación de las víctimas; si bien es cierto se cuenta con la colaboración de la Procuraduría para la Defensa de los Derechos Humanos bajo un carácter consultivo -como señaló el presidente Funes en su discurso- no es suficiente para una representación de los ofendidos. En esa línea, la participación del Ministro de Defensa, general David Munguía Payés, despierta insatisfacciones, pues su investidura militar lo hace juez y parte en la búsqueda de la verdad y la justicia. En definitiva, resulta incongruente que en la balanza de la comisión estatal pese más la representación del Ejército, uno de los más significativos artífices de las violaciones a los Derechos Humanos, sobre el sector hasta ahora plenamente marginado. Asimismo, el Ejército, a pesar de formar parte del ejecutivo, está llamado a reconocer sus errores y contribuir con plena disposición a la reparación moral, de igual forma lo deberá hacer el FMLN, más allá de la petición de disculpa realizada por Salvador Sánchez Cerén. Respecto a la reparación material y a la voluntad de saldar la deuda moral es válido señalar, más allá de los recursos financieros disponibles en el Estado, que es más pertinente saldar primero la deuda desde el establecimiento de la verdad y la justicia, lo cual lleva a considerar que el perdón no está separado de la última, más bien la aplicación de ésta lo reafirma. Se trata pues de una reparación como la han hecho otros paises que sufrieron de igual forma que el nuestro, es decir, con acciones concretas en el ámbito legal, con obras de reparación simbólicas, exhumaciones, entre otras. Considerar en primer plano la reparación material 
se podría correr el riesgo de realizar una mera indemnización, dejando de lado el señalamiento a los culpables, y, por tanto, parte del compromiso histórico con las víctimas, con sus familiares, con el reconocimiento del pasado para ubicar el presente y superar, con certeza, la impunidad que prevalece en el país.

Ciertamente, pedir perdón en nombre del Estado es el primer paso al reconocimiento de las víctimas, pero no lo garantiza. El reconocimiento y la reconciliación pasa por otras decisiones como la ya citada derogación de la ley de Amnistia, esto es, por el cumplimiento de la justicia, más allá que ésta sea o no punitiva. La justicia bien puede ser restaurativa, es decir, una justicia que no excluya el señalamiento a los responsables de los crímenes, que, a su vez, pueda ofrecer dignidad para las víctimas, dignidad desde el reconocimiento y la compensación moral, psicológica y material. Justicia para el pasado tan necesaria para lograr la justicia social que el país necesita. En ese sentido, el presidente Funes sentó las bases para el saneamiento moral de la sociedad salvadoreña, a partir del 16 de enero del 2010 El Salvador reinició otro derrotero, se trata del tránsito hacia una mayor democratización, todos los sectores e instituciones del país involucrados -y sus representantes- están llamados a obrar por la honra de las víctimas, se abre pues la posibilidad de hacer efectivos los Acuerdos de Chapultepec. 